\title{
Perspectivas Sobre A Economia Solidária E A Produção Do Espaço Gonçalense
}

\author{
Maíra Vieira do Vale ${ }^{1}$
}

\section{Resumo}

Diante do cenário atual de desemprego exacerbado, deterioração e flexibilização das relações de trabalho e intensas críticas ao modelo econômico dominante, aumentam-se as lutas travadas pelos movimentos sociais e emergem iniciativas que rompem com os limites do mercado formal de trabalho, propostas de desenvolvimento econômico, social, cultural, ecológico e político pautadas nos princípios da Economia Solidária. Alternativa ao desemprego, possibilidade de gestão coletiva, fonte de complemento de renda ou o acesso ao crédito estão entre as principais motivações para a criação dos Empreendimentos Econômicos Solidários.

Este trabalho busca contribuir para a reflexão sobre a atuação do movimento de Economia Solidária na produção do espaço gonçalense, integrante da Região Metropolitana do Rio de Janeiro. A pesquisa baseia-se na leitura de bibliografia especializada, análise dos dados oficiais do Mapeamento Nacional e acompanhamento de experiências solidárias atreladas ao Fórum Municipal de Economia Solidária, espaço misto de debate e troca livre de experiências que busca contribuir para a construção de políticas públicas de trabalho dentro dos princípios solidários e promoção social no município e viabilizar projetos entre a sociedade civil organizada, iniciativa privada e o poder público local.

Palavras-chave: Economia solidária, trabalho, espaço.

\section{Abstract}

Before the current situation exacerbated unemployment, deterioration and flexibility of work relations and intense criticism of the dominant economic model, increase the struggles waged by social movements and emerging initiatives that break through the boundaries of the formal market of work, economic development proposals Social, cultural, ecological and political guided by the principles of Solidarity Economy. Alternative to unemployment, the possibility of collective management, a source of additional income or access to credit are among the main motivations for the creation of enterprise economic solidarity.

This paper seeks to contribute to the reflection on the performance of the Solidarity Economy movement in the production of space gonçalense, a member of the Metropolitan Region of Rio de Janeiro. The research is based on the reading of specialized bibliography, analysis of official data from the National Mapping and monitoring of cooperative experiences linked to the Municipal Forum of Solidarity Economy, mixed area of debate and free exchange of experiences that contributes to the construction of public policies work within the principles of solidarity and social development in the 


\section{REVISTA TAMOIOS}

municipality and facilitate projects between civil society organizations, private organizations and local government.

Key words: Solidarity Economy, work and, space

\section{Introdução}

Carregada de contradições, a década de 1990 traz a intensificação da economia informal frente ao contexto de crise sócio-econômica, marcada de um lado pelo encolhimento da atuação do Estado, desemprego exacerbado, flexibilização das relações de trabalho, fragilização dos sindicatos, por outro pelo aumento da capacidade de exploração dos recursos naturais, inserção do Brasil no projeto neoliberal e intensificação da participação na globalização. Os anos noventa trazem como traço forte o aumento das lutas travadas pelos movimentos sociais, intensos debates sobre a exclusão e críticas ao modelo econômico dominante.

Neste cenário emergem iniciativas que rompem com os limites do mercado formal de trabalho, propostas de desenvolvimento econômico, social, cultural, ecológico e político pautadas nos princípios da Economia Solidária como a gestão democrática da atividade econômica, emancipação de trabalhadores e trabalhadoras como sujeitos históricos e valorização do meio ambiente. Nota-se uma enorme expansão e consolidação (quantitativa e qualitativa) do movimento de Economia Solidária (ES) em diversos cantos do país, seja como alternativa ao desemprego, possibilidade de gestão coletiva, fonte de complemento de renda ou como forma de facilitar o acesso ao crédito.

O momento atual exige mudança de postura em prol da distribuição de renda igualitária, não como uma medida governamental de cima para baixo que tutele os mais pobres. Uma postura que incentive a tomada de consciência da população para que ela seja o agente de reivindicação. Desta forma, aquele modelo jurídico de cunho marcadamente liberal e indiferente às lutas pelos direitos populares, precisa ser suplantado por um modelo inclusivo, que assume obrigações perante os cidadãos e dialoga com os anseios de diferentes atores sociais.

Entre as décadas de 1990 e 2000 é possível identificar uma expansão dos empreendimentos econômicos solidários em São Gonçalo (MTE, 2009). O município destaca-se em termos populacionais (o segundo mais populoso do Estado do Rio de Janeiro com 999.901 habitantes, IBGE, 2010) não somente na escala metropolitana ou estadual, mas também na escala macro-regional da Região Sudeste e está entre os 10 maiores produtos internos brutos do estado. Chegou a ser chamado de Manchester Fluminense durante as décadas de 1940 e 1950.

Além de integrar a Metrópole do Rio de Janeiro, faz parte do Complexo Petroquímico do Rio de Janeiro (Comperj ${ }^{2}$ ) e abriga o centro de inteligência do Comperj (ainda em fase de instalação), além de ter assento no Consórcio Intermunicipal da Região Leste Fluminense, (Conleste) ${ }^{3}$. 
O município conta com diferentes movimentos sociais populares. 0 Fórum Municipal de Economia Solidária atua, por exemplo, no âmbito construção de políticas públicas de trabalho, emancipação dos trabalhadores e articulação entre a sociedade civil organizada, iniciativa privada e o poder público local.

\section{Resultados}

\section{Características gerais dos empreendimentos econômicos solidários gonçalenses}

As reflexões a seguir têm como base de dados apenas os empreendimentos que o Mapeamento Nacional SIES/SENAES 2005/2007 conseguiu visitar, num total de 26 em São Gonçalo. Possivelmente este valor não abarca toda a gama de $E E S^{4}$ existentes no município.

Para esta reflexão, faz-se necessário compreender a categoria trabalho. $\mathrm{Na}$ Geografia buscamos analisar a relação da mesma com a produção do espaço geográfico, no qual Santos considera:

O espaço é formado por um conjunto indissociável, solidário e também contraditório, de sistemas de objetos e sistemas de ações, não considerados isoladamente, mas como o quadro único no qual a história se dá. [...] Sistemas de objetos e de ações interagem. De um lado, os sistemas de objetos condicionam a forma como se dão as ações e, de outro lado, o sistema de ações leva à criação de objetos novos ou se realiza sobre objetos preexistentes. É assim que o espaço encontra a sua dinâmica e se transforma. (2008a, p. 63)

Integrante de ambos os sistemas, os resultados do trabalho fazem parte do sistema de objetos e as relações intrínsecas a ele fazem parte do sistema de ações. Como o espaço é uma construção social, o trabalhador, através de sua atividade contribui na produção do espaço. Desta forma, o trabalho transforma o espaço e também se transforma a partir das relações e interações entre resultados e relações trabalhistas.

O trabalho ainda se faz presente na realidade social enquanto elemento analítico para se explicar estruturas, conflitos e ações sociais. Não devemos analisar as conjunturas econômicas e sociais atuais pautados apenas na categoria trabalho, mas sim um analisar um conjunto de fatores, o que não significa dizer que tenha perdido seu papel e/ ou que esteja em curso um processo de crise ou de implosão da sociedade do trabalho.

Como já mencionado, a década de 1990 é um marco em âmbito nacional no que diz respeito à presença da economia informal frente ao contexto de crise de postos de trabalho formais. A partir deste período é possível identificar uma expansão dos empreendimentos econômicos solidários em São Gonçalo, que seguem aumentando na década de 2000 (ver tabela 1) Entre as motivações de primeira ordem (tabela 2) declaram, respectivamente, fonte de complemento de renda para os associados, alternativa ao 


\section{REVISTA TAMOIOS}

desemprego, obtenção de maiores ganhos em um empreendimento associativo, possibilidade de gestão coletiva onde todos são donos.

Tabela 1. Quantidade de EES por ano de início em São Gonçalo: Mapeamento 2005/2007

\begin{tabular}{c|c|c|c|c|c|c}
\hline $\begin{array}{c}1900 \text { a } \\
1950\end{array}$ & $\begin{array}{c}1951 \text { a } \\
1970\end{array}$ & $\begin{array}{c}1971 \text { a } \\
1980\end{array}$ & 1981 a 1990 & $\begin{array}{c}1991 \text { a } \\
2000\end{array}$ & $\begin{array}{c}2001 \text { a } \\
2007\end{array}$ & TOTAL \\
\hline- & - & - & 3 & 9 & 14 & 26 \\
\hline
\end{tabular}

Fonte: Silva, Catia Antonia da et al. Atlas do Trabalho na Metrópole do Rio de Janeiro. São Gonçalo: FFP- UERJ - no prelo.

Tabela 2. O que motivou a criação dos EES em São Gonçalo: Mapeamento 2005/2007

\begin{tabular}{|c|c|c|c|c|}
\hline MOTIVOS & $\begin{array}{c}\text { ORDEM } \\
1\end{array}$ & ORDEM 2 & ORDEM 3 & TOTAL \\
\hline $\begin{array}{l}\text { 1. Uma alternativa ao } \\
\text { desemprego } \\
\text { 2. Obtenção de maiores ganhos } \\
\text { em um empreendimento } \\
\text { associativo }\end{array}$ & 4 & 5 & 1 & 10 \\
\hline $\begin{array}{l}\text { 3. Uma fonte complementar de } \\
\text { renda para os(as) } \\
\text { associados(as) } \\
\text { 4. Desenvolvimento de uma } \\
\text { atividade onde todos são donos }\end{array}$ & 4 & $\begin{array}{l}1 \\
1\end{array}$ & $\begin{array}{l}2 \\
0\end{array}$ & $\begin{array}{l}9 \\
5\end{array}$ \\
\hline $\begin{array}{l}\text { 5. Condição exigida para ter } \\
\text { acesso a financiamentos e } \\
\text { outros apoios } \\
\text { 6. Recuperação por } \\
\text { trabalhadores de empresa } \\
\text { privada que faliu }\end{array}$ & 1 & 0 & 0 & 1 \\
\hline $\begin{array}{l}\text { 7. Motivação social, filantrópica } \\
\text { ou religiosa } \\
\text { 8. Desenvolvimento comunitário } \\
\text { de capacidades e } \\
\text { potencialidades }\end{array}$ & 2 & 2 & 1 & 5 \\
\hline $\begin{array}{l}\text { 9. Alternativa organizativa e de } \\
\text { qualificação } \\
\text { 10. Outro. Qual? }\end{array}$ & $\begin{array}{l}1 \\
1\end{array}$ & $\begin{array}{l}2 \\
1\end{array}$ & $\begin{array}{l}0 \\
0\end{array}$ & $\begin{array}{l}3 \\
2\end{array}$ \\
\hline
\end{tabular}

Fonte: Silva, Catia Antonia da et al. Atlas do Trabalho na Metrópole do Rio de Janeiro. São Gonçalo: FFP- UERJ - no prelo. 


\section{REVISTA TAMOIOS}

A venda e troca de produtos ou serviços destinam-se, sobretudo, a escala local - comércio local ou comunitário e diminuem conforme aumenta o nível hierárquico. Poucos atingem os mercados estadual, nacional e internacional (ver tabela 3).

\section{Tabela 3. Principais destinos de venda e a troca de produtos e/ou serviços dos EES em São Gonçalo: Mapeamento 2005/2007}

\begin{tabular}{l|c|c|c|c}
\hline \multicolumn{1}{c|}{ DESTINO } & ORDEM 1 & ORDEM 2 & ORDEM 3 & TOTAL \\
\hline Comércio local ou comunitário & 11 & 7 & 1 & 19 \\
\hline Mercado/comércio municipal & 3 & 5 & 0 & 8 \\
\hline Mercado/comércio micro- & 7 & 1 & 3 & 11 \\
regional & 1 & 0 & 1 & 2 \\
\hline Mercado/comércio estadual & 3 & 0 & 0 & 3 \\
\hline Mercado/comércio nacional & 1 & 0 & 0 & 1 \\
\hline Exportação para outros países &
\end{tabular}

Fonte: Silva, Catia Antonia da et al. Atlas do Trabalho na Metrópole do Rio de Janeiro. São Gonçalo: FFP- UERJ - no prelo.

Os próximos dados (tabela 4) demonstram a predominância de EES atuantes em áreas urbanas e uma presença menor em áreas rurais. A existência, mesmo que pequena, do segundo tipo de EES contradiz os dados oficiais, constando que o município é cem por cento urbano (PMSG, 2009b). No entanto, a própria Prefeitura Municipal através da subsecretaria de Agricultura e Pesca promove a Feira do Produtor Rural, espaço onde os produtores expõem produtos como, aipim, coco, doces, temperos, mel, cachaça, quiabo, maxixe, jiló, milho, banana, laranja, laticínios, hortaliças entre outros produtos. Nos panfletos turísticos, afirma-se que todos os produtos são produzidos em terras gonçalenses e reconhece-se que no município há uma considerável área rural com a presença de várias propriedades destinadas à produção agrícola, neles podemos encontrar a propaganda de turismo rural apresentando fazendas da região, como por exemplo, a Fazenda Itaitindiba e o Sítio Girassol. Incluem cavalgada, pesque e pague, feira de produtos rurais, passeios de charrete, comidas, etc. Portanto, os usos do território nem sempre são levados em consideração. De fato a característica urbana de São Gonçalo baseada em suas atividades econômicas é proporcionalmente maior, movimentam-se mais recursos com produtos urbanos que rurais, todavia, "urbanizar" o município pode ser rentável, pois possibilita uma grande arrecadação de imposto predial e territorial urbano (IPTU). 
Tabela 4. Área de atuação dos EES em

São Gonçalo: Mapeamento 2005/2007

\begin{tabular}{l|r}
\hline \multicolumn{1}{c|}{ ÁREA } & \multicolumn{2}{|c}{ TOTAL } \\
\hline Rural & 2 \\
\hline Urbana & 19 \\
Rural e urbana & 5 \\
\hline TOTAL & $\mathbf{2 6}$ \\
\hline
\end{tabular}

Fonte: Silva, Catia Antonia da et al. Atlas do Trabalho na Metrópole do Rio de Janeiro. São Gonçalo: FFP- UERJ - no prelo.

\section{O Fórum municipal de economia solidária de São Gonçalo}

Para compreender as estratégias de acesso ao mundo do trabalho em contextos metropolitanos e dialogar com as experiências do movimento de economia solidária no município de São Gonçalo, faz-se necessário reconhecer à metrópole ${ }^{5}$ como território da diversidade, de múltiplos usos. Território concentrador da problemática enfrentada pelo trabalhador, das políticas públicas de trabalho, emprego e geração de renda, dotado de relações de poder inscritas na produção do espaço (SILVA E RIBEIRO, 2009).

Não há unanimidade no uso do termo economia solidária, são diversas as interpretações e variados os graus de consciência e organização. Sem a intenção de criar um conceito fechado e acabado, é possível identificar pontos de convergência, como a valorização social do trabalho humano; a busca de uma relação de intercâmbio respeitoso com a natureza; o projeto de uma sociedade justa e equilibrada; a busca pela socialização da riqueza e pela gestão democrática da atividade econômica.

A economia solidária, marcada pela elevada tensão entre distintas racionalidades e lógicas de ação, se desenvolve dentro de uma formação social capitalista. Assim como o movimento das mulheres, o movimento ambientalista, suas bandeiras transcendem o debate classista. Existem várias realidades de manifestação e os atores são muitos, entre eles: empreendimentos e redes de cooperação, entidades de apoio, acessoria e fomento, órgãos públicos, gestores de políticas, programas e projetos de Economia solidária. Em termos de escala, o movimento organiza-se em fóruns locais (municipais ou regionais), fóruns estaduais e o fórum brasileiro, vale destacar que uma das lutas é por uma globalização humanizadora.

O emprego não representa um fim em si mesmo, suas bandeiras ultrapassam o caráter emergencial. Não é somente voltado para a questão de trabalho, do desemprego, nem todas as experiências solidárias são de caráter econômico, os grupos organizam-se, entre outros fins, por exemplo, para agir no espaço público, no plano da conquista de direitos básicos. Ou seja, a economia solidária não está fechada em si mesma, inclusive, articula-se a outros movimentos sociais. Transmite valores, conflitos, propõe a redefinição de praticas societárias cotidianas. 


\section{REVISTA TAMOIOS}

Além do plano de desenvolvimento econômico, de trabalho e renda, os debates têm dimensão de raça, de gênero, cultural, ecológica, econômica, política, entre outras, e aparecem junto com temas como consumo responsável, comércio justo, transformações sociais, direitos de cidadania, exclusão, sociedade civil, democracia, desenvolvimento local sustentável, etc.

O Fórum Municipal de Economia Solidária de São Gonçalo (FMESSG) se apresenta como um espaço misto de encontro e militância, aberto para o debate democrático de idéias, a formulação de propostas, a troca livre de experiências, a articulação para realizações de ações eficazes e elaboração de estratégias de mobilização de entidades e movimentos da sociedade civil. A economia solidária não realiza milagres e não quer substituir a ação pública pela caridade. Precisa, portanto, de regulamentações internacionais, nacionais e locais. Busca contribuir para a construção de políticas públicas de trabalho no município. Possui uma forte identidade com o Fórum Municipal Lixo e Cidadania de São Gonçalo (FMLCSG) ${ }^{6}$, os dois fóruns realizam muitas ações conjuntas.

O FMESSG é também um espaço de formação e reflexão em direção a alternativas de sociedade e geração de renda, que diminuam os efeitos negativos da atual relação capital versus trabalho. Em São Gonçalo o fórum reúne artesãos; catadores de materiais recicláveis; costureiras; líderes comunitários; grupos informais (de produção, serviços, de consumo); pesquisadores; representantes do poder público (secretarias de governo, de meio ambiente, de cultura, do trabalho), de grupos sócio-educacionais, de universidades, de cooperativas, de associações; organizações não governamentais e de outros movimentos sociais (exemplo do movimento de mulheres).

As mobilizações pré-fórum iniciaram em dezembro de 2006, a partir da união de artesãos, empreendimentos, instituições sociais, poder público dentre outros que se reuniam através dos encontros mensais da Rede Social da Ong Guardiões do Mar, espaço no qual se colocava em prática discussões voltadas para essa linha de ação. Assim, de rede social foi se transformado em fórum e ganhou legitimidade para pensar em projetos que viabilizem o desenvolvimento local. Recebeu apoio do Programa de Promoção do Desenvolvimento Local e Economia Solidária (PPDLES) e passou a ser parte integrante do Fórum Brasileiro de Economia Solidária (FBES).

A primeira lista de presença oficial data 03 de maio de 2007, ano em que o mesmo se consolidou. As reuniões, chamadas entre os participantes de plenárias, servem para tomar ciência, avaliar e decidir coletivamente as ações a serem realizadas. O fórum, como visto anteriormente, é aberto, logo a população pode comparecer aos encontros. Todos que assistem a plenária, seja para conhecer o que vem sendo realizado em São Gonçalo no que diz respeito à economia solidária, seja para fazer contatos entre os diversos setores presentes, têm direito a participação nas decisões. Os participantes contribuem voluntariamente contribuem para as atividades do fórum, conforme suas disponibilidades.

Tem um público fixo e outro flutuante. Como é característico dos movimentos sociais, há momentos de bastante expectativa e vigor, marcados por reuniões lotadas, contando inclusive com a presença de participantes de outros estados brasileiros e até mesmo internacionais, como pesquisadores 
estrangeiros, mas há outros momentos esvaziados, como o atual, com um público muito reduzido.

Devemos considerar que "um município, seja qual for o seu tamanho, além de território, ou melhor, por sê-lo, é antes de tudo um conjunto de lugares", "o município tem também uma função simbólica de identidades num nível acima das experiências cotidianas" (Simões, 2007, p. 42-43). Os participantes do fórum, em geral, construíram identidades com o município, portanto, desejam desenvolvê-lo e não abrem mão de participar ativamente dos diversos processos decisórios do poder público. Seus militantes se fazem presentes em várias audiências públicas e acompanham os orçamentos municipais, a destinação e aplicação dos mesmos.

Os principais objetivos do FMESSG são: fortalecer os empreendimentos solidários; disseminar os conhecimentos em economia solidária, através de encontros, seminários, cursos, feiras, troca de experiências com outras cidades; viabilizar projetos entre a sociedade civil organizada, iniciativa privada e o poder público local; articular os fóruns e pré-fóruns do leste metropolitano; criar um conselho municipal de economia solidária; fomentar políticas públicas de trabalho dentro dos princípios solidários e de desenvolvimento sustentável; buscar programas de apoio à criação e sustentação de espaços fixos para a comercialização; acompanhar os orçamentos municipais e a execução (aplicação) dos mesmos nos EES; buscar estratégias de fomento à ES no estatuto da cidade; criar um Centro Municipal de Referência em Economia Solidária (ES) e uma estrutura Regular para o Fórum; inserção da ES na legislação municipal; elaborar ferramentas de potencialização de redes e cadeias de produção, comercialização, consumo e comunicação entre empreendimentos e divulgar os produtos; articular-se com outros movimentos sociais do município, promovendo ações conjuntas frente ao executivo e ao legislativo; criar uma frente parlamentar suprapartidária de apoio.

Para fortalecer os empreendimentos e fomentar a criação de novos, discuti-se sobre políticas públicas de incentivos, por exemplo, isenções fiscais, assim, como há para as grandes empresas. Discuti-se acerca de marcos regulatórios próprios para as demandas locais da economia solidária.

Trabalha em conjunto com o Fórum Brasileiro de Economia Solidária (FBES) e com o Fórum de Cooperativismo Popular do Rio de Janeiro (FCP).

Conta com barracas próprias (doadas) e organiza-se em grupos de trabalho (Gts) que são formados à medida que as necessidades e dificuldades surgem ou aumentam, são eles: Finanças solidárias; Produção, consumo e comercialização; Marco Legal; Formação e Comunicação. Ao Gt de Finanças solidárias compete pensar em financiamentos para a economia solidária. $O$ artesão consegue confeccionar seu produto em qualquer lugar, mas comercializar não, estas são questões debatidas no Gt de Produção, consumo e comercialização. Compete ao Marco Legal estudar as leis que orientam a Economia Solidária e pensar como flexibilizá-las junto aos tributos, é necessário que o tratamento da Economia Solidária seja diferenciado. O GT de Formação busca entender o que é Economia Solidária, refletir, debater, pensar em ações a fim de desenvolver a cultura da Economia Solidária, formar cursos (informática, economia solidária, etc.).

O FMESSG tem buscado realizar uma articulação com os municípios de seu entorno (por exemplo, Tanguá, Itaboraí, e Niterói), incluindo a criação de uma rede e de uma cadeia produtiva solidária a fim de fortalecer o movimento. 
Apoiou a criação do Fórum Municipal de Economia Solidária de Tanguá, que continua prosseguindo e o de Itaboraí, que se encontra momentaneamente parado. Tem procurado promover um diálogo aberto com instituições que pensam o trabalho no município e, especialmente, com os trabalhadores.

Aproximou-se dos pesquisadores do Rio Democracia (Observatório de favelas), da Faculdade de Formação de Professores da UERJ/São Gonçalo (FFP), da Secretaria Municipal de Trabalho, da Casa Brasil ${ }^{7}$ entre outros.

Através do GT de comercialização e visando incentivar iniciativas populares e gerar trabalho e renda, o FMESSG organiza feiras de artesanato com exposição e venda de produtos feitos por artesãos locais, como roupas, acessórios, objetos de decoração, utilidades para o lar, moda, bolsas, doces caseiros entre outras novidades. Este GT busca parcerias para viabilizar um local permanente de exposição e comercialização de produtos da economia solidária, promover a troca de experiências entre os artesãos e divulgar os dois fóruns locais.

O grupo de artesãos do município trabalha com diversas linhas de artesanato feitos com muita criatividade e habilidade: materiais recicláveis, fibras vegetais, frutas, sementes, bordado, tecelagem, barro, pedra, renda, pintura, bijuterias, crochê, tecido (fuxico, customização, etc.), entre outros. As feiras costumam incluir também uma programação cultural (apresentações de capoeira, teatro, danças e jogos) ao final do expediente, valorizando assim, o saber local. Ou seja, a feira não é simplesmente uma atividade comercial, além da inclusão produtiva, busca promover também a inclusão social. Cogita-se a possibilidade de adoção de moeda social para a realização das feiras de economia solidária no município.

Visando a aproximação entre a universidade e o movimento social para a realização de discussões e fomento de pesquisa, extensão, ensino, produção e disseminação do conhecimento de ES, formalizou-se em 2008 o Projeto "Metodologia de Educação Urbano-Ambiental no Município de São Gonçalo", em parceria com a UERJ/FFP.

Uma das principais lutas do movimento tem sido a criação de um Centro de Referência de Economia Solidária que atue junto a Secretaria Municipal de Trabalho (SEMTRAB/SG), assim como já existe em outros municípios e reservar um espaço só para tratar desta questão, proporcionando uma sensação de pertencimento. Esta proposta prevê um trabalho em conjunto, envolvendo sociedade e poder público local.

Uma outra articulação foi a aproximação com o Projeto Casa Brasil, unidade São Gonçalo, a fim de disseminar o conceito de economia solidária através de cursos de formação, cursos de informática e promover a inclusão social de trabalhadores e empreendimentos. Alguns cursos já foram realizados.

Participa de seminários e encontros em âmbito estadual e nacional através de representantes votados coletivamente. Atuou junto com o FMLCSG e outras instituições no Seminário "Enfrentando os Desafios dos Resíduos Sólidos". Apoiou a criação do sistema de finanças solidárias Casa da Confiança, que, com o lema "Dinheiro da Gente nas Mãos da Gente", capta recursos das pessoas e entidades do FCP-RJ e os coloca a serviço das mesmas. Organizou debates e feiras em parceria com a UERJ/FFP.

É uma experiência que faz parte de um movimento nacional e global, envolvendo diferentes atores e setores sociais. Vale reconhecer que muitos também se aproximam do fórum para tirar vantagens. 


\section{REVISTA TAMOIOS}

O poder público municipal já vem reconhecendo o potencial da catação e da atividade artesanal, inclusive criou dois decretos a respeito deste segundo ramo de atividade. Um decreto regulamenta o funcionamento das feiras de artesanato e o outro das feiras de troca no município, respectivamente, $\mathrm{n}^{\circ}$ 248/2005 e n²49/2005:

[...] Considerando a necessidade de disciplinar 0 funcionamento das Feiras de Artesanato realizadas em logradouros públicos do Município, de modo a proteger a atividade artesanal, divulgar e preservar a produção artística dos munícipes, [...] (PMSG, 2005a)

[..] A Prefeita do município de São Gonçalo, no uso de suas atribuições, considerando a necessidade de instituir disciplinar 0 funcionamento das Feiras de Troca realizadas em logradouros públicos do município, de modo a proteger a atividade de troca e venda de objetos usados... (PMSG, 2005b)

Contudo, na elaboração desses documentos não houve um diálogo os com os artesãos, o que põe em dúvida se a posição da prefeitura é, de fato, fortalecer e proteger a atividade artesanal e a atividade de troca e venda de objetos usados, como consta nos trechos retirados dos decretos acima citados, ou controlar.

\section{Considerações Finais}

Assunto de crescente interesse público, seja no meio acadêmico, sindical ou nas outras organizações da sociedade civil, as formas de trabalho associado e cooperado vêm ganhando espaço e reconhecimento, fazendo parte da pauta das ações do governo federal. Contudo, diante de todos os avanços, ainda há muitos desafios a serem superados, inclusive a ampliação e efetivação de políticas públicas enquanto ações promovidas pelo Estado, com participação dos movimentos sociais e capazes de garantir a sociedade os direitos básicos.

O movimento social é um campo de conflitos onde existem diferentes sentidos de disputa. A economia solidária está em processo de formação, sistematização, traz mudanças de atitudes, mas ainda não é revolução. Desenvolve-se dentro de uma formação social capitalista e é marcada pela elevada tensão entre distintas racionalidades e lógicas de ação. Entretanto, as suas formas de manifestação têm conquistado a emancipação de trabalhadores e trabalhadoras como sujeitos históricos, demonstrando-se um caminho viável e sustentável de desenvolvimento local e por isso devem ser apoiadas e preservadas.

\section{Notas}

1- Geógrafa; Professora da rede estadual e Pós-graduanda da Especialização em Dinâmicas urbano-ambientais e Gestão do território (UERJ/FFP):

vieira.maira@gmail.com 


\section{REVISTA TAMOIOS}

2- Com início de operação previsto para 2012, o Comperj tem como principal objetivo aumentar a produção nacional de produtos petroquímicos (setor de produção de resinas termoplásticas e combustíveis) e estabelecer o Estado do Rio de Janeiro como um pólo de oportunidades de negócios no referido setor. (AGENDA 21 COMPERJ, 2009)

3- O Consórcio Intermunicipal da Região Leste Fluminense é composto pelos municípios de Itaboraí, Niterói, São Gonçalo, Cachoeiras de Macacu, Casimiro de Abreu, Guapimirim, Magé, Maricá, Rio Bonito, Silva Jardim e Tanguá. Tem como principais propósitos promover a organização das estratégias, decisões e atuações conjuntas diante dos possíveis impactos referentes ao projeto do Comperj e também atrair, com mais facilidade, diversos investimentos para seus respectivos municípios.

\section{4- Empreendimentos Econômicos Solidários}

5- A categoria metrópole ultrapassa os limites da de Região Metropolitana (RM), a segunda é objeto de planejamento regional, delimitada pelos governos estaduais visando à adoção de uma administração integrada e de políticas públicas comuns. Por exemplo, a realização de serviços urbanos afins, não representando, necessariamente a real relação cotidiana, econômica e trabalhista entre seus integrantes. Por trás de uma administração integrada, guarda objetivos políticos e econômicos não divulgados. Enfim, a mesma não expressa uma verdadeira vida metropolitana entre os municípios que a compõem, mas, sobretudo, o jogo de interesses entre os políticos locais.

6- Fórum Municipal Lixo e Cidadania de São Gonçalo (FMLCSG) é constituído por cidadãos, entidades governamentais e não governamentais com sede no município. Também é um espaço aberto para recolher contribuições técnicas, favorecer o debate e a articulação das ações conjuntas, com o objetivo central de influenciar nas políticas públicas, reunindo experiências de instituições e personalidades que atuam no campo dos resíduos sólidos e da promoção social. Seu papel é favorecer a discussão e a apresentação de soluções para os problemas surgidos em torno desta temática no município.

7- O projeto Casa Brasil, de caráter interministerial do Governo Federal, busca democratizar as comunicações, levando às comunidades de baixo índice de desenvolvimento humano computadores (telecentro), sala de leitura, auditório, ações em tecnologias livres (software livre) aliadas a cultura, arte, entretenimento, articulação comunitária e participação popular. (Ministério da Ciência e Tecnologia, 2009)

8- O evento reuniu especialistas, estudiosos, pesquisadores, parlamentares, catadores e empresários, realizado no município de São Gonçalo, auditório do SEST/SENAT. 


\section{Referências Bibliográficas}

AGENDA 21 COMPERJ. 0 Comperj. Disponível em <http://www.agenda21comperj.com.br>. Acesso em 08 de junho de 2009.

ANTUNES, Ricardo. As Metamorfoses do Mundo do Trabalho. Adeus ao trabalho?: ensaio sobre as metamorfoses e a centralidade do mundo do trabalho. - 11. ed. - São Paulo: Cortez; Campinas, SP: Editora da Universidade Estadual de Campinas, 2006.

. Dimensões da precarização estrutural do trabalho. In: DRUCK, Graça; FRANCO, Tânia (orgs.). A perda da razão social do Trabalho: terceirização e precarização - São Paulo: Boitempo, 2007, p. 13-22.

ARROYO, João Cláudio Tupinambá; SCHUCH, Flávio Camargo. A questão do crédito. In: ARROYO, João Cláudio Tupinambá; SCHUCH, Flávio Camargo. Economia popular e solidária: a alavanca para um desenvolvimento sustentável e solidário - 1. Ed. - São Paulo: editora Fundação Perseu Abramo, 2006, p. 73-80. - (Coleção Brasil Urgente).

CUNHA, Gabriela Cavalcanti. Dimensões da luta política nas práticas de economia solidária. In: SOUZA, André Ricardo de; CUNHA, Gabriela Cavalcanti; DAKUZAKU, Regina Yoneko (orgs.). Uma outra economia é possível: Paul Singer e a economia solidária. São Paulo: Contexto, 2003, p. 45-72.

IBGE. Censo 2010: primeiros dados divulgados. Acessado em 05 de janeiro de 2011. Disponível em:

http://www.ibge.gov.br/censo2010/primeiros_dados_divulgados/index.php?uf=3 3

MINISTÉRIO DO TRABALHO E EMPREGO. Atlas da Economia Solidária no Brasil, 2005. Brasília: MTE, SENAES, DED, 2006.

MINISTÉRIO DO TRABALHO E EMPREGO. Atlas da Economia Solidária no Brasil, 2005-2007. ANTEAG - São Paulo: Todos os bichos, 2009.

PMSG. Atos oficiais: Decreto n o 248/2005. São Gonçalo: PMSG, 07 de setembro de 2005a. Disponível em < http://www.pmsg.rj.gov.br>.

PMSG. Atos oficiais: Decreto n o 249/2005. São Gonçalo: PMSG, 07 de setembro de 2005b. Disponível em < http://www.pmsg.ri.gov.br>.

PMSG. Economia. Prefeitura Municipal de São Gonçalo Disponível em $<$ http://www.saogoncalo.ri.gov.br>. Acesso em abril de 2009a.

Secretaria do meio Ambiente. Disponível em
<http://www.saogoncalo.ri.gov.br>. Acesso em 12 de junho de 2009b. 


\section{REVISTA TAMOIOS}

PMSG. Estatísticas. Disponível em < http://www.pmsg.ri.gov.br >. Acessado em 15 de outubro de 2010.

QUEDES. Marilde Queiroz. Trabalho na perspectiva marxista. Disponível em: <www.fasb.edu.br $>$. Acesso em junho de 2008.

SANTOS. Milton. Técnica, Espaço, Tempo. In: SANTOS, Milton. Técnica, Espaço, Tempo: Globalização e Meio Técnico-Científico Informacional. 3. ed. São Paulo: Hucitec, 1997a, p 61- 86.

. O Espaço: Sistemas de Objetos, Sistemas de Ação. In: Santos, Milton. A Natureza do Espaço: Técnica e Tempo, Razão e Emoção / Milton Santos. 4. ed. 4. reimp. - São Paulo: Editora da Universidade de São Paulo, 2008a, p. 61-87 - (Coleção Milton Santos; 1).

. Os Dois Circuitos da Economia Urbana dos Países Subdesenvolvidos. In: SANTOS, Milton. O espaço divido: Os Dois Circuitos da Economia Urbana dos Países Subdesenvolvidos. - 2. ed, 1 reimp. - São Paulo: Editora São Paulo: Editora da Universidade de São Paulo, 2008b, p. 29-82. - (Coleção Milton Santos; 4).

SILVA, Catia Antonia da. Crise da modernidade trabalho em contextos metropolitanos. In: Formas em crise: utopias necessárias. Rio de Janeiro: Arquimedes Edições, 2005a, p. 23-46.

. et al. Atlas do Trabalho na Metrópole do Rio de Janeiro. São Gonçalo: FFP- UERJ - no prelo.

Mutações no mundo do trabalho, contexto sócio-espacial e secularização: estratégias de sobrevivência na Metrópole do Rio de Janeiro. In: SIMPURB, XX, 2005, Manaus. Anais do XX SIMPURB. Manaus: 2005b.

; RIBEIRO, Ana Clara Torres. Metrópole, trabalho e contextos da vida coletiva: algumas reflexões sobre a dimensão espacial da tecnologia social e da economia solidária. In: BACAYUVA, Pedro Cláudio Cunca; VARANDA, Ana Paula de Moura (organizadores). Tecnologia social, economia solidária e políticas públicas. 1. ed. - Rio de Janeiro: FASE: IPPUR, UFRJ, 2009.

SIMÕES, Manoel Ricardo. Concepções teóricas acerca das emancipações políticas. In: A cidade estilhaçada: reestruturação econômica e emancipações municipais na baixada Fluminense. Mesquita: ed. Entorno, 2007, p. 39-67.

TOURAINE, Alain. Os movimentos sociais. In: Foracchi, Marialice \& Martins, José de Souza (Orgs.). Sociologia e Sociedade (leituras de Introdução à Sociologia). Rio de Janeiro. Livros técnicos e Científicos, 1977. 